Revista Letras,

Curitiba, n. 94 jun./dez. 2016. ISSN 2236-0999

\section{La guerra de los textos, los textos en la guerra}

Pablo Rocca *

\title{
RESUMEN:
}

Este artículo indaga algunos aspectos de la cultura letrada durante la Guerra Grande (1843-1851) tanto en la ciudad sitiada, Montevideo, como en el gran territorio dominado por los sitiadores. Se indaga sobre el papel que desempeñaron los mediadores del impreso (tipógrafos, impresores), sobre cuánto pesó en la formación de los lectores la enseñanza y la propia práctica de las lenguas europeas - en especial el francés y el inglés -, que ensancharon las posibilidades de conocer el mundo moderno. Y, por último, sobre cómo fue o cómo pudo ser el consumo de la nueva narrativa - dentro de ella, desde luego, las formas de la novela histórica - que con los años afirmó la idea moderna de ficción y propició el surgimiento de una ficción local.

Palabras-clave: Guerra Grande (1843-1851); ficción; públicos.

\section{Resumo:}

Este artigo pesquisa alguns aspectos da cultura letrada na época da Guerra Grande (18431851) tanto na cidade cercada, Montevidéu, quanto no grande território dominado pelos sitiadores. Importa, neste artigo, estudar qual foi o papel que desenvolveram os mediadores dos impressos (tipógrafos, impressores); quanto pesou na formação dos leitores o ensino e a prática das línguas européias - em especial o francês e o inglês -, que ampliaram as possibilidades de conhecer o mundo moderno. E, por ultimo, como foi o como poderia ter sido o consumo do novo romance - dentro dele, claro, as formas do romance histórico - que com os anos afirmou a idéia moderna de ficção e facilitou o nascimento de uma ficção local.

Palavras-chave: Guerra Grande (1843-1851); ficção; públicos.

Abstract:

This article inquiry some problems into the literary culture during the Guerra Grande (1843-1851) in the besieged city, Montevideo, and in the countryside dominated by the besiegers. It is paramount to analyze the role played by the "print mediators" (typesetters, printers), the weight of the teaching and practice of European languages -specially French and English- which widened the possibilities of attaining knowledge about the modern world, and, finally, the characteristics of how the perusal of the new narrative -and within it, of course, the forms of the historical novel- was (or might have been), which eventually supported the modern notion of fiction itself and the future emergency of the local fiction.

Keywords: Guerra Grande (1843-1851); fiction; publics.

\footnotetext{
${ }^{\star}$ Universidad de la Republica (Montevideo, Uruguay)
} 
A un después de 1843, cuando comenzó la Guerra Grande - como la hambre de pan y de futuro. A ese gran puerto natural, libre de graves amenazas durante casi todo el conflicto, arribaban otros que pronto iban a ser muy necesarios. Desde distintas partes de Europa, desde la otra orilla del Plata bajo el dominio de Rosas, desde Brasil o incluso desde Chile iban y venían letrados, pero también artesanos y obreros preparados para la difusión de la escritura y la imagen.

Pese a la guerra, larga y devastadora para una zona en incipiente formación, la lectura y la escritura maduraron por el auspicioso proceso formativo general de aquel estrecho espacio físico en el que se amontonaban algunos miles de seres, repartidos entre una mitad de nacidos en el país y otra mitad de extranjeros. Para 1843 era fuerte la presencia de quienes eran capaces de sostener discusiones y promoverlas en varios impresos -públicos o particulares- tanto en español como en otras lenguas; por último, pero no menos importante, al menos hasta fines de la década del cuarenta hubo una afluencia significativa de mano de obra apta para producir impresos. Esos debates políticos e ideológicos lejos de cubrir todas las expectativas convivieron con la poesía y cada vez más con la narrativa, en especial las novelas por entregas difundidas en los periódicos, la mayor parte 
Rocca, P. La guerra de los textos, los textos en la guerra traducidas del francés.

Un periódico que salía de lunes a viernes en Montevideo, el Comercio del Plata (1845-1858), publicó 1.850 números hasta la firma de la paz, en octubre del 51, y fue dirigido por el notable exiliado argentino Florencio Varela hasta cierta noche de marzo de 1848 en que fue asesinado en la puerta de su casa. Dentro de la ciudad asediada, en la que empezaron a brotar periódicos que, a menudo, se hundían para volver a emerger (Praderio, 1962), el Comercio del Plata aporta la mayor y mejor información sobre la idea de literatura más al día. En este periódico se registra la mayor cantidad de relatos de ficción, por él transcurren reflexiones sobre la naturaleza de los públicos, en él se hallan datos valiosos sobre los artesanos, sobre los medios materiales de impresión y, por último, sobre la enseñanza de lenguas durante el sitio. Todas estas piezas son engranajes del mismo circuito de producción, trabajo y práctica cultural, que algunos -como Florencio Varela- pronto se dieron cuenta de que era necesario amalgamar para obtener mejores resultados. Ya en su primer número, del $1^{\circ}$ de octubre de 1845, el editorial del periódico define un proyecto de doble raíz local y ecuménica, porque siendo "americanos de nacimiento y de corazón [...] no comprendemos entre los intereses Americanos y los Europeos diferencias que los hagan incompatibles, $y$ menos que deban mantenerlos en lucha [...]" (col. 3). Al amparo de estas compatibilidades nace una política editorial:

Ocuparemos una parte de la tercera y cuarta páginas en la publicación de una série de obritas, orijinales ó traducidas, que procuraremos siempre que sean relativas á la América; y que formarán una colección de libros útiles, bajo el título de Biblioteca del Comercio del Plata.- La forma de publicación es la misma que se ve en este número: ella permite cortar las cuatro páginas del libro, para encuadernarlas oportunamente, dejando intacto el resto del diario. Los índices, títulos y demas se darán gratis á los subscriptores al concluir cada obrita, y lo mismo la carátula jeneral de cada tomo de la Biblioteca, cuando se halle completo. [...] La publicación de nuestra pequeña Biblioteca será independiente de la del Folletín, que destinaremos únicamente á escritos agradables. Poseemos una cantidad de cuentitos y novelillas realmente interesantes, traducidas expresamente para llenar con toda regularidad nuestro Folletín; mientras no podemos realizar el pensamiento que nos ocupa de llenarse con anécdotas y episódios de la historia americana, revestidos de forma literaria, y que no pertenezcan, por eso, al jénero de escritos, que formará la Biblioteca.

Esperamos que nuestro Folletín tendrá por lectores 
Rocca, P. La guerra de los textos, los textos en la guerra principales la bella porción de nuestra Sociedad, que no puede hallar interés directo en el Comercio, que aparta con horror sus ojos de las escenas que hoy ofrece la situación política de estos países; que se hiela con razón, al ver columnas de guarismos en la Estadística; que tiene miedo al mar, para leer la Marítima; y que, después de satisfecha la curiosidad ilustrada y seria, que procura imponerse de lo que pasa en el Exterior, se reposa, con placer, en la lectura agradable de un Folletín ( $\left.\mathrm{N}^{\mathrm{o}} 1,2-3\right)$.

La tajante distinción entre Biblioteca y folletín divide al público. Asigna, por un lado, a los hombres cultos como si fuera algo natural -libreto entonces corriente-, el destino social y cívico aliado al ejercicio del pensamiento. Por otra parte, otorga a las mujeres el lugar de la imaginación algo gratuita análoga al margen de una pasividad en que privaba el entretenimiento alimentado por "cuentitos y novelillas". Esa división territorial deja al descubierto dos cosas discontinuas: primero, una perspectiva limitada al predominio masculino y burgués; segundo, que el conocimiento de los avances del periodismo moderno se pondrían al servicio de sus propósitos. En esas condiciones cualquier impreso tiene relevancia, y el Comercio del Plata quiere presentarse como una pequeña colección de temas y textos contemporáneos de difícil acceso, textos escritos en otras lenguas y a los que se encargará de facilitar en traducción. Es decir, la traducción como efecto modernizador y actualizador de los debates sin los cuales no es posible construir la urgente ciudadanía en peligro de ser arrasada, de un momento a otro, por el enemigo que se identifica con la peor barbarie (Rosas y su aliado Manuel Oribe), la traducción como santo y seña de una lengua que debe ensanchar sus horizontes más allá de cualquier resabio colonial.

Salvo alguna excepción aislada, en aquellas circunstancias editar en libro estos escritos era un camino cerrado por los altos costos, por el riesgo continuo de que los insumos importados de pronto podrían cortarse, por un mercado restringido a unos pocos kilómetros cuadrados y a unos poquísimos millares de lectores. De ahí que los redactores de Comercio del Plata cuiden la integridad física del ejemplar del periódico que no se ve afectado cuando se recorta cada entrega de la Biblioteca. El mismo periódico importa como material para archivar, para releer. Este se preservará cuando se recorte la página de la Biblioteca impresa de los dos lados en forma invertida para que, una vez encuadernada con las subsiguientes, forme un cuadernillo al que se agregarán otros para componer al cabo un libro. ${ }^{1}$

Si emprendimientos como el de una colección de temas y problemas americanos eran minoritarios, en su lugar, como en toda América (como en

1 Eso ocurrió con la colección completa encuadernada, que hemos consultado, que perteneció al investigador y erudito bibliófilo Horacio Arredondo. Antes de llegar a sus manos no sabemos quién era su propietario. Hoy se preserva en la Biblioteca central de la Facultad de Humanidades y Ciencias de la Educación de la Universidad de la República.
Revista Letras,

Curitiba, n. 94 p. 106-126, jun./dez. 2016. ISSN 2236-0999 
Rocca, P. La guerra de los textos, los textos en la guerra

toda Europa), la novela en folletín empezó a leerse con avidez. Algunos autores, como Alexandre Dumas antes que nadie, quien sería protagonista fundamental en 1850 cuando se publique en Francia Montevideo ou Une Nouvelle Troie, habían logrado una enorme y rápida aceptación justo cuando el conflicto estalló en la primera mitad de los cuarentas. El Comercio del Plata se sirvió de esta fuerza y trató de encauzarla. En esa planta baja del periódico no se ofrecieron sólo narraciones sino diferentes tipos de escrituras, porque como antes en Francia, según lo advirtió Marie-Eve Thérenty, el folletín fue un laboratorio de escritura, un espacio de experimentación discursiva que se sirvió de los problemas del día y que contagió con su retórica al mismo medio de prensa que lo alojaba (Thérenty, 2013). Sintomáticamente, en temprano homenaje de Eugène Sue, el periódico reprodujo en la sección "Folletín" el poema de la española Carolina Coronado “A Mr. Eugenio Sue por su obra El judio errante”. Más que la alabanza en sí, los versos finales, traspuestos por los editores al contexto rioplatense, hablan de su intención por defender la lengua francesa, su cultura y su pathos, contra el modelo español tan castigado, antes, por Sarmiento o por Alberdi o por Lamas:

\author{
Vos sois francés, la Francia os merecia: \\ pero no es patria mía; \\ y al ensalzar vuestro glorioso nombre \\ añado, tristemente: \\ ¡oh, Dios omnipotente! \\ ¿por qué no es español tan grande hombre!...
}

$\left(\mathrm{N}^{\mathrm{o}} 60,11\right.$ de diciembre 1845,1$)$

En la misma dirección, pero más sardónicamente, otro texto publicado a fines de 1857 en la revista La Semana, escrito por una mujer que no firma o por un hombre que defiende los derechos de las mujeres y no se expone demasiado, responde al habitual menosprecio de las capacidades reflexivas de las damas. En ese relato, "La caja de costura (Cuadro de Lèo Lespés, contorneado por una señorita)", litigan madre e hija. La primera afirma la necesidad de que las jóvenes se dediquen a las tareas de la casa eligiendo la "caja de costura" como metonimia y metáfora de la sujeción al varón y al hogar, y condena el "pérfido" territorio de la lectura de novelas; la segunda, llamada (irónicamente) María, postula que mejor se invierte el tiempo leyendo "un romance de Sué ó de Alejandro Dumas" que tejiendo crochet o cortando una pollera. Su madre, tras la cual se esconde la ideología patriarcal en estado crudo, responde escandalizada que "preferir los romances y las novelas á los trabajos de agujas, [...] sería lo mismo que preferir la pizarra al diamante", sentencia con la cual el narrador busca diseminar el efecto contrario de sentido (Anónimo, 1990, 211-215). Una vez más, la doble referencia afirma la identificación de la novela folletinesca con la literatura francesa y fija dos autoridades: la de dos creadores populares que 
Rocca, P. La guerra de los textos, los textos en la guerra se habían impuesto los años anteriores y, por otra parte, ya que Lèo Lespés es uno de los muchos heterónimos de Delphine de Girardin (1804-1855) cabe la posibilidad de que el texto atribuido hasta ahora a un autor (o autora) rioplatense en rigor haya sido una pieza traducida en Montevideo o en algún lugar donde se escriba en español. Como sea, este espiral de identidades que se solapan ponen el asunto de la escritura de mujeres y las figuras del lector en el centro de la escena, europea o americana.

"Cuentitos y novelillas", a pesar del desprecio que trasunta el diminutivo, serán difundidos por el elitista Comercio del Plata porque sus hacedores saben que complacerá a un público mayor que, por eso mismo, podrá suscribirse para recibir el divertimento de lecturas nuevas. Un divertimento imprescindible para soportar los momentos más amargos, siempre y mucho más durante una guerra que ni por asomo da señales de agotarse cuando se publica ese plan, el $1^{\circ}$ de octubre de 1845. Cuando entonces se estaba, además, en el clímax de la novela en folletín en Europa. Apenas un año antes habían aparecido las tres ficciones que consagraron la nueva forma narrativa (Les trois mousquetaires, Le Comte de Montecristo y Le juif errant).

En rigor, los antecedentes para la lectura de estas narraciones masivas eran muchos y fuertes, sobre todo de la prosa romántica que en las décadas anteriores habían tomado por asalto la sensibilidad de muchos lectores en todas partes. Como lo demostró Marlyse Meyer esas novelas fueron las más solicitadas en los gabinetes de lectura franceses, pero también en los de Rio de Janeiro. Es el caso de Célestine, ou Les époux sans l'être, Les enfants de l'abbaye ou Amanda et Oscar y Saint-Clair des Isles (Meyer, 2005, 35).

Ni en Montevideo -ni en el Cerrito, denominación que se asignó al gobierno de los sitiadores- conocemos la existencia de gabinetes de lectura. Si acaso, un poco antes, Jaime Hernández, librero e impresor español radicado en Montevideo en 1830, adonde llegó con el oficio de tipógrafo, pudo compensar la ausencia de un cabinet de lecture con la oferta de muy nutridas obras narrativas (Rocca, 2015).

A fines de 1837 la Librería de Hernández registró sus existencias en un catálogo que salió de imprenta poco después (Catálogo ..., 1838). A juzgar por fuente tan relevante la poesía se retraía limitada a pocas decenas de volúmenes de escaso interés contemporáneo; tenían su lugar destacado los libros de religión, de historia, de ciencia, así como los diccionarios y gramáticas, pero el reino de la novela había triunfado. La mejor librería de la ciudad ofrecía entretenida narrativa castellana de antaño, como el Quijote (nueve ejemplares, que certifican 
Rocca, P. La guerra de los textos, los textos en la guerra
Revista Letras,

Curitiba, n. 94 p. 106-126, jun./dez. 2016. ISSN 2236-0999 un interés sostenido, cuatro de ellos con láminas de autor no identificado) o sus novelas ejemplares (cuatro volúmenes) o el Persiles (también cuatro) o el Lazarillo de Tormes (apenas uno). Hasta donde nos es posible escrutarlos, dentro de la confusión general de autores y títulos que se acumulan esa lista de 1837 , alrededor de cien piezas narrativas se ofrecían en el catálogo de don Jaime Hernández en un total de dos centenares, esto es al menos un 50\% del total de las existencias de la librería.

Hay historias que se encontraban en ese comercio que continuaron siendo muy populares en diferentes lenguas hasta un siglo y pico después. Por ejemplo, Bertoldo y Bertoldino (un ejemplar), ${ }^{2}$ Matilde o las Cruzadas, de Madame Cottin (seis ejemplares), que ochenta años más tarde seguiría leyéndose -tal vez por el prestigio adquirido en la primera mitad del siglo XIX- y se volvería a publicar en traducción por la activa (y popular) Biblioteca de la Nación de Buenos Aires, dirigida por Roberto J. Payró, editor de Machado de Assis en ese sello (Rocca, 2012). También se puede ubicar Olimpia o los bandoleros de los Pirineos, muy probablemente en la edición valenciana de la Imprenta de Gimeno, donde se había tirado un año atrás, según hemos podido verificar en viejos catálogos españoles. Hernández tenía en su comercio dos libros que fueron clave -como lo demostró Adolfo Prieto- para fundar una imagen de América para los europeos, pero también para los escritores hispanoamericanos: Atala o el Amor de dos salvajes en el desierto, de Chateaubriand (1801) y Último Mohicano (The Last of the Mohicans, 1826), de Fenimore Cooper, la novela americana más leída durante décadas en todas las Américas, la novela de aventuras que, además, inspiró a Sarmiento en su Facundo (1845) para comparar al nativo de la Pampa con el habitante del far west.

Hay, también, en ese catálogo otros títulos menos ligados a la historia de la alta literatura, pero que han sido fundamentales para los lectores y sus literaturas en América Latina. Se ofrece Oscar y Amanda o los descendientes de la Abadía (tres ejemplares), la misma historia que se leía mucho en Brasil, según lo ha documentado Marlyse Meyer. Idéntica cantidad de tomos podía encontrarse de Saint Clair de las Islas, novela escrita y publicada en inglés en 1803 por Elizabeth Helme, adaptada al francés un lustro después por Madame Isabelle de Montolieu y retraducida a otras lenguas desde esta fuente indirecta que, en rigor, servía para América Latina como matriz. El ejemplo merece una pausa.

Luís da Câmara Cascudo y Marlyse Meyer demostraron que Saint Clair

2 Se me permitirá un testimonio que algún valor tiene para el caso. En mi familia, de origen italiano y de escasas letras, habían pasado de mano en mano a lo largo de dos generaciones dos libros que recuerdo vívidamente: Corazón, de Edmundo d'Amicis, cuyas historias -en una edición en rústica, seguramente española, profusamente ilustrada a carbonilla- me leían a fines de la década del sesenta con la esperanza de forjar mi sensibilidad. También, en un ejemplar in $8^{\circ}$ con una cubierta muy colorida, de algo que hoy puedo calificar como cierto expresionismo popular, mi padre atesoraba un Bertoldo, Bertoldino y Cacaseno, uno de los pocos libros que hacia comienzos del siglo xx había pertenecido a su padre. Estas historias, algo más jocosas y bruscas, se me leían a medias. Con no poca sorpresa descubrí algunos años más tarde que esta literatura podía ser reutilizada para formas más complejas en El juguete rabioso, de Roberto Arlt (1926). 
Rocca, P. La guerra de los textos, los textos en la guerra
Revista Letras,

Curitiba, n. 94 p. 106-126, jun./dez. 2016. ISSN 2236-0999 de las Islas, novela de asunto medieval y caballeresco, promovida como "histórica" para otorgar un contrato de verosimilitud mayor a la materia narrada -episodios de crímenes constantes, historias de amor, lealtad y traición- excitó la imaginación popular en diversos puntos de Brasil. Esta evidencia la resaltó Guimarães Rosa en Grande sertão, veredas (1956), cuando dentro de su ficción recupera a Saint Clair..., que ha perdido la autoría entre sus admiradores, proceso típico de la literatura popular. Los habitantes de lo más profundo del sertão mineiro en la versión de Guimarães fragmentan el relato del cual se apropian reorganizándolo en sus constantes trasmisiones y desde esas historias interpretan el mundo. Aunque pasó algo inadvertido hay otro episodio clave para la historia contemporánea de Brasil, en que se mezclan lectura, ficción, realidad cruda y violencia. Con menor repercusión mucho tiempo antes y desde una perspectiva refractaria a este tipo de textos, pudo pensarse la interpolación entre imaginario popular y literatura folletinesca. Al comienzo de la Guerra do Contestado un artículo anónimo del Diário da Tarde de Curitiba, datado en octubre de 1912, señala que una de las causas fundamentales para atizar la rebelión de los campesinos insurrectos ha sido las "leituras de Carlo Magno", una de las tantas historias que se difundieron en toscos folletos vulgarizando las hazañas del héroe medieval en sus aspectos más violentos. Debemos este hallazgo a Marilene Weinhardt, quien lo ha exhumado en un libro fundamental para pensar las fronteras entre ficción histórica, crónica, testimonio, periodismo y otros discursos que registran o evocan esa terrible guerra afincada en el estado de Paraná (Weinhardt, 2000, 38-39). Nada semejante pudimos hallar en el Río de la Plata, durante este período sobre la díada violencia política y representación literaria en el campo específico de las prácticas de los de pocas letras fuera, claro está, de las apropiaciones de estas voces realizadas por los poetas gauchescos, fenómeno sobre el cual la bibliografía ya es caudalosa.

Para 1840 también triunfaba el registro de la novela sentimental. En los estantes de la Librería de Jaime Hernández descansaban nueve ejemplares de Clara Harlowe (1794), de Samuel Richardson, la mayor de las existencias del total bibliográfico de la casa. Esta extensa novela se había traducido al español apenas dos años después de su edición original y en 1829 volvió a publicarse en París y también en Madrid en tres volúmenes, en rigor retraduciéndola del francés. ${ }^{3}$ Hasta ahora, ninguna historia nacional de la literatura de cada uno de los países del Río de la Plata, ya que increíblemente no existe ninguna que los conjunte, ha registrado el más mínimo eco de la presencia de estas ficciones marginales

3 Por la proximidad de la fecha tal vez Hernández ofertaba la edición titulada Historia de Clara Harlowe. Novela traducida del inglés al francés por $M^{r}$ Le Tournier, siguiendo en todo la edición original revista por su autor Richardson, y del francés al castellano por D. José Márcos Gutiérrez. Segunda ed. corregida y enmendada. Madrid, Imprenta de Repullés, 1829. (Ápud. https://books.google.com. uy/books?id=JXG1GZoUun4C\&pg=PA10\&lpg=PA10\&dq=clara + harlowe\&source=bl\&ots=QfHREsMWD7\&sig=4DuIn357DaPp2kZss24sPBiUU5E\&hl=es\&sa=X\&ved=0ahUKEwivhc6wv_MAhXCph4KHUyjB0sQ6AEIazAN\#v=onepage\&q=clara\%20harlowe\&f=false (Consulta realizada el 29/V/2016). 
Rocca, P. La guerra de los textos, los textos en la guerra al canon. Sin ellas, como ya es ostensible, no se hubiera construido ninguna literatura vernácula, ya sea como escritura ya en cuanto prácticas de recepción individuales y colectivas.

La ficción podía aportar a los adolescentes otros escapes para su imaginación o abría a los adustos señores una salida para sus preocupaciones diarias; hasta los niños de las clases acomodadas pudieron obtener mejores posibilidades de entretenimiento en el acto de leer. Las mujeres empezaron a participar de modo activo en el mercado imaginario, ahora no sólo (o no exclusivamente) leyendo vidas de santos, devocionarios o catecismos -como el famoso del Padre Astete, del que en la Librería de Hernández hay un solo ejemplar a fines del 37- sino, sobre todo, leyendo novelas más o menos complejas y, si acaso, libros de esos que hoy se llaman de autoayuda que, con sus estereotipos, procuraban compensar represiones surtidas, como Mujer sensible (del que había un ejemplar) o Mujer feliz (tres piezas). Por esos mismos años nos ha llegado el testimonio de un testigo privilegiado y lúcido de la vida rioplatense, el culto francés Benjamin Poucel, quien después de un pasaje por Montevideo en 1845 ya estaba radicado en el oeste del territorio, en el departamento de Colonia, dedicado a las tareas rurales. Cuando los gobiernos de Francia y de Inglaterra intervinieron a favor de Montevideo, el jefe de los sitiadores, el General Manuel Oribe, como indiscriminada represalia, dio la orden de tomar prisioneros a todos los ciudadanos de este origen que encontró en el vasto territorio bajo su mando. Entre ellos fue detenido Poucel, a quien se condujo desde el extremo oeste hacia el centro del país, al pueblo de Durazno. En Les otages de Durazno, libro extraordinario en el que se desborda el apunte autobiográfico sobre ese raro cautiverio que le permitía circular entre los límites de un pueblo rústico, Poucel observó que la educación de las mujeres orientales era muy deficitaria; no así su inteligencia y sensibilidad:

[...] ante la falta de objetivos y de maestros para emprender estudios serios, las jóvenes se dedican generalmente al estudio de las lenguas vivas. Como son muy capaces, aprenden con facilidad inglés, italiano, portugués y, sobre todo, francés. Su preferencia por esta última lengua se debe a su afición por la lectura de nuestras novelas principalmente, esos dulces venenos mezclados con flores... En definitiva, estudian poco, pero leen y mucho (POUCEL, 2001, 45).

En otros términos, habría que creer que el género impulsaba la cultura letrada desde mujeres de la burguesía (alta o media) que, alrededor de 1840, sobre todo leían novelas francesas, mientras otras mujeres y hombres (por qué no) poco o nada familiarizados con el francés podían leerlas en las frecuentes traducciones de la prensa montevideana. Ese aceitado motor de la ficción nueva 
Rocca, P. La guerra de los textos, los textos en la guerra conspiraba contra la idea de ciudadanía que buscaban los letrados de las nuevas naciones, quienes trataban de crear una literatura por mediación de la europea sin que esto supusiera debilitamiento alguno de ideas y sentires americanos, un mito urgente y de complejísima construcción. Quizá ese modelo de novela alcanzó la primera pieza admisible para sus propósitos en Amalia, del argentino José Mármol (luego exiliado en Brasil), que comenzó a publicarse en La Semana de Montevideo en 1851, en la que se mezcla una historia sentimental con la denuncia de la contemporánea tiranía rosista. O pudo tolerarse en la posterior Caramurú (circa 1855), de Alejandro Magariños Cervantes, en la que otra historia de amor -ahora entre un gaucho y una doncella hija de estanciero- procura acercarse al lenguaje, las costumbres y la naturaleza de la región.

Con brillante y violenta claridad en 1853 Sarmiento hizo el deslinde entre estos discursos que evoca la distinción entre la biblioteca americana y las "novelillas" de la que habló Florencio Varela en su editorial del diario montevideano. Las siguientes anotaciones de Sarmiento sobre producción, lectura, públicos y novela aparecen intercaladas en un informe sobre la educación argentina, en el que capitalizó otros trabajos similares realizados en el exilio chileno desde una década atrás:
A la Biblia, pues, se han sucedido los libros profanos, y entre estos libros, vergüenza da decirlo y hasta profanación parece, las novelas han sido y continúan siendo hasta hoy el estimulante a la lectura, en los pueblos que, como los nuestros, carecen de nociones generales, de historia propia, de debates religiosos o políticos, y de nociones científicas de industria. ¡Las novelas! Así tan inmorales como las clasifican todos, las novelas son el primer libro que despierta el deseo de leer, que deja nociones en el espíritu, y corrompiendo como se dice, rescatan a muchos del entorpecimiento que trae la falta de toda emoción comunicada por un pedazo de papel escrito. No hacemos el elogio de la novela, cuando quisiéramos, por el contrario, sustituirle [por] libros más provechosos. Señalamos un hecho de todos conocido. Las imprentas americanas no producen otro libro para la general lectura, porque es el único que encuentra lectores y compradores.

¿Hay otros libros que el Don Quijote o el Gil Blás de Santillana, que estén en cierta proporción generalizados en América? Nosotros no conocemos sino El Judío Errante y los Misterios de París; pero en uno y otro caso no vemos sino el hecho material de las numerosas ediciones que de ellos se han hecho en español, por donde se ha logrado que una buena porción de ejemplares se difunda en la sociedad (Sarmiento, 
Rocca, P. La guerra de los textos, los textos en la guerra
1949, 449-450).

Los debilísimos estados platenses podían hacer muy poco contra esta literatura. La educación había incorporado sólo un porcentaje pequeño de la población, excluyendo a la mayoría de las mujeres quienes, como muchos varones, si acaso se alfabetizaban en sus hogares o en pequeñas instituciones particulares. La Biblioteca Nacional de Montevideo se había refundado, después de múltiples postergaciones y tropiezos, poniéndola en manos del poeta Francisco Acuña de Figueroa, y juntándola a las funciones de Museo Nacional. Pero vegetaba casi huérfana de presupuesto y de funcionarios (Mascaró y Sosa, 1882; Scarone, 1916).

Contra los deseos de fortalecimiento de una literatura local se acelera la traducción de novelas sentimentales y de aventuras. A la vanguardia de los impresos, la novela ayuda a impulsar el periodismo incorporando más lectores que los que arrimaban los estudios de situación o los escritos polémicos. Hacia 1845 el nuevo proyecto simbólico avanza junto a una adecuada infraestructura técnica, capaz de mantenerlo con vida, como puede verse en la nota que también sale en el número inicial con el título "Imprenta del Comercio, Calle de Misiones ${ }^{\circ} 88$ ":

Este establecimiento tiene grande abundancia de tipos de todas clases, elegantes, y enteramente nuevos; signos de astronomía, matemáticas, medicina, y demás que se usan en obras científicas; una fundición de caracteres griegos; las letras y acentos estraños a la lengua española, pero que se usan en las extranjeras; jerolificos (sic) y adornos de todas clases; hermosas prensas de fierro muy perfeccionadas; y en una palabra, todo lo que constituye una excelente Imprenta.

Los directores conocen los idiomas ingles, frances, italiano, portugues y latino (sic); pueden atender por sí mismos á la corrección de los trabajos que se encarguen en esos idiomas, dándolos tan depurados de errores tipográficos como los escritos en el idioma del país.

Los que encarguen alguna obra podrán poner el papel de su cuenta, ó elegir entre las varias clases del que tiene la casa, según mejor les convenga.

La Imprenta solo será responsable de los errores de impresión y ortografía; pero no de otras faltas, que haya en los 
Rocca, P. La guerra de los textos, los textos en la guerra originales que se la remitan.

Los precios nunca serán más altos que en otras Imprentas, en igualdad de circunstancias.

Toda obra, sin ecepcion, se pagará totalmente, ántes de llevarla de la casa.

Otro aviso del 16 de mayo del 46 pauta los avances en la edición y encuadernación de los incipientes talleres gráficos locales. Contra las adversidades imperantes, además de periódicos e imprentas la ciudad cercada ya tiene obreros gráficos y artesanos para ocuparse de diferentes renglones en la factura del libro. Suficientes, incluso, como para que en 1843 se forme una "compañía de tipógrafos” del ejército de reserva al mando del librero Jaime Hernández con el grado de capitán (восса, 2015). Como al pasar, un aviso sobre Viajes a la América meridional, de Félix de Azara, permite calibrar un cierto público que, aun en pequeñas proporciones, absorberá este producto:

Esta obra, que forma por sí sola el $2^{\circ}$ volumen de la Biblioteca del Comercio del Plata, se halla á la venta e la oficina de este diario, á patacon y medio el ejemplar.

Los que le quieran encuadernar pagarán á mas exactamente lo que tome el encuadernador, segun la clase de forro que se pida ( $\mathrm{N}^{\mathrm{o}}$ 180, 16/V/1846, 4, col. 3).

Otros talleres eran capaces de imprimir hojas, periódicos y trabajos de mayor envergadura. En el mismo Comercio se daba cuenta de que la Imprenta de la Caridad se modernizaba mientras cambiaba su razón comercial: "Habiendo pasado este Establecimento á manos de una nueva sociedad, se ofrece al público para hacer toda clase de trabajos á precios sumamente acomodados; para lo que cuenta con un elegante surtido de tipos, viñetas, adornos, etc." ( $\left.\mathrm{N}^{\mathrm{o}} 101,31 / \mathrm{I} / 1846,3\right)$. Por lo demás, si muchos tipógrafos y linotipistas vivían de su oficio quizá también los encuadernadores podían mantenerse con el suyo. El 23 de diciembre de 1845 Juan Marella, quien por su apellido tal vez era un italiano recién llegado a Montevideo, da a publicidad en el Comercio del Plata que es "Encuadernador, ofrece sus servicios en este ramo. Trabaja á la rústica, en media pasta, y pasta entera á precios moderados. Vive calle de Alzaybar $N^{\circ} 11$, tras del Fuerte" ( $\mathrm{N}^{\mathrm{0}} 70,4$, col. 2). Puede que alarmado por la competencia, unos días después, el 16 de enero, un señor de evidente origen germano no quiso ceder terreno y buscó un nicho de mercado en el área burocrática: "C H. Kuhr. Encuadernador de libros. Calle del Sarandí $N^{\circ} 125$. Hace todas las clases de papel rayado, tanto para libros de comercio, como para cuentas y papeles de oficina" ( $\mathrm{N}^{\mathrm{0}} 80,3$, col. 2). La misma actividad profesional desempeñaba un francés de apellido Lagouardère, quien con el oficio de encuadernador se registró en la Legión Francesa, donde sirvió con el 
Rocca, P. La guerra de los textos, los textos en la guerra grado de segundo teniente, y así aparece firmando un documento colectivo en marzo de 1850 (Braconnay, 1943, 167).

Durante la guerra la única frontera abierta de Montevideo fue el puerto. Aun en ese borde del aislamiento mejoraron las posibilidades físicas para la lectura. Porque el puerto abría a Montevideo al mundo y, a pesar del endeudamiento constante y endémico a medida que se prolongaba el conflicto, la ciudad se servía de bienes importados de la Europa que iniciaba su proceso de industrialización.

En las construcciones montevideanas de tipo colonial, hasta en las más sólidas, cuando se retiraba la luz natural el tiempo de sus habitantes yacía en los ambientes más bien inhóspitos y penumbrosos. En vísperas de la guerra, durante 1842, llegaron algunas soluciones que combatieron la oscuridad y amenizaron las horas de descanso en el hogar y, entre otras actividades recreativas, la lectura pudo hacerse con mayores comodidades. Jorge Grünwaldt explica que por entonces empezó a ceder el maloliente humo de la vela de sebo, usual en los hogares más pobres, generalizándose "la vela esteárica, fabricada en el país y que antes se importaba de limpia y brillante llama”. En cuanto aumentan los medios económicos crecen las posibilidades, porque para la "familia acomodada [...] en la sala, en el comedor y en los dormitorios reina el refinado quinqué importado [...] de Francia e Inglaterra [...] que el montevideano alimenta con aceite de pata, con aceite de oliva - a la española- o mejor con aceite de esperma, caro, pero de impecable combustión" (Grünwaldt, 1970, 36).

IV

La educación básica y la enseñanza de lenguas extranjeras apuntaló, entre los más jóvenes, ese incremento de los estímulos en el hábito de leer para todos los que conocían la técnica. La escolarización siguió creciendo en Montevideo y no fue descuidada en el campo sitiador, donde Oribe mandó levantar un enorme edificio con fines educativos, el Colegio Nacional, del que se sentía muy orgulloso en vísperas de su ejecución, según lo cuenta en sus notas el norteamericano Samuel Greene Arnold, quien se entrevistó en el 47 con el rígido jefe del asedio y en su compañía pudo examinar los planos de la obra (1951, 131-132).

En 1846, la ciudad sitiada tenía doce escuelas particulares de niños y nueve de niñas, un Colegio francés, un seminario inglés y la escuela oficial dirigida por Antonio Lamas. Precipitadamente, y sin que nadie lo planificara, Montevideo había conquistado una inmensa ganancia, sacaría una fortaleza en un contexto de otros debilitamientos con la multiplicación de maestros particulares de

4 Se trata del predio que luego, y hasta hoy, fue convertido en hospital, que lleva el nombre de Pasteur.
Revista Letras,

Curitiba, n. 94 p. 106-126, jun./dez. 2016. ISSN 2236-0999 
Rocca, P. La guerra de los textos, los textos en la guerra diversas lenguas. A su vez, esta enseñanza introducía a los jóvenes en el mundo de la lectura de novelas cuando el género estaba en su apogeo. "La educación de las niñas -dice Grünwaldt-era disputada por damas francesas principalmente, entre ellas las señoras Bercoêt, Guyot, Daret, las señoritas Lesueur" (Grünwaldt, 1970, 75). Los enseñantes (o, mejor, las enseñantes) de francés como sin quererlo se metían en las casas de las jóvenes de los sectores más favorecidos, las de la numerosa colonia francesa y las de los originarios del país. No sólo estos porque los ingleses también hacían su contribución, como se revela, entre otros, en este ilustrativo aviso del Comercio del Plata del 16 de octubre de 1845:

IDIOMa INGLÉs. Mr. Duffy profesor de lengua Inglesa, y conocedor igualmente de la Gramática Castellana, ofrece sus servicios al público en la enseñanza de aquella lengua, en la que ha formado muchos y buenos discípulos. Tiene un curso abierto para los jóvenes en el Colejio Oriental, calle de las Camaras núm 36, en el que piensa, sin tardar, hacer ver á los Señores padres de familia los rápidos progresos de sus discípulos por medio de unos exámenes. Da igualmente clases particulares en las casas á las personas que tenga [sic] a bien honrarle con su confianza. Vive en la calle de Solis núm $87\left(\mathrm{~N}^{\circ}\right.$ 14, 4, col. 1).

Con la mayoría de los hombres dedicados al terrible arte de la guerra, las mujeres con alguna preparación que acababan de llegar a la ciudad, y que carecían de recursos básicos para sobrevivir, se vieron forzadas a buscar trabajo. Tuvieran o no formación pedagógica algunas se ofrecieron para enseñar su lengua, tal vez con buena recepción entre la comunidad local. Esa energía se renovó después de la paz del 51. Sólo tomando los datos proporcionados por la Guía de Montevideo, año primero, editada en 1859, en su importante biografía de Isidore Ducasse, nacido en Montevideo durante el sitio en el 46, el investigador Jean-Jacques Lefrére contó treinta y dos establecimientos de educación primaria, diez de ellas privadas entre las cuales ocho se dedicaban prioritariamente a la enseñanza del francés (Lefrère, 1998, 71). Antes, en plena guerra, francesas e inglesas y tal vez algunas italianas salieron a conquistar el mercado de trabajo ocupando este renglón decisivo de la enseñanza de la lengua junto a algunos pocos hombres que venían de ultramar: "Una señora francesa recien llegada de París, se compromete á dar lecciones de francés en casas particulares, á aquellas Señoritas que quieran favorecerla con su confianza. Vive en la calle de Misiones, número 65, donde podrán verla las personas que la necesiten" (Comercio del Plata, Montevideo, $\mathrm{N}^{\mathrm{O}} 86$, 14/I/1846, 4, col. 1). Junto a otras formas desesperadas de conseguir ingresos lo mismo sucedió con "Una señora inglesa. Se propone enseñar un número corto de niños y niñas en el idioma, escritura y aritmética; calle de Canelones $N^{\circ} 15$. En la 
Rocca, P. La guerra de los textos, los textos en la guerra

misma casa se alquilan dos ó tres piezas, $y$ se venden varios muebles". ${ }^{5}$

En la Villa Restauración hubo señoras y señores franceses que ofrecieron sus servicios de preceptores, como lo ha documentado Mateo Magariños de Mello. No sólo -cabe conjeturar-para obtener los consabidos medios económicos sino, en tal caso, para paliar una carencia severa de conocedores de estas lenguas en un ambiente mucho más precario de letras y lenguas, en el que dominaba lo criollo, lo hispánico y sobre todo lo católico contra la marca más cosmopolita y masónica de Montevideo gobernada por colorados locales y unitarios porteños.

La enseñanza y difusión del francés permitirá que esta lengua y su cultura -sobre todo de su literatura- deje una marca que durará un siglo largo en la sociabilidad uruguaya. Aquellas desocupadas damas y los modestos profesores algo improvisados serán decisivos para captar la atención de los jóvenes por el francés para el prestigio de la lectura en esa lengua a las que cultivaron acercándose a una ficción que los atraía, mientras se transformaba con el folletín como medio y como forma.

En la primera mitad de 1850 llegó a Montevideo el escritor Xavier Marmier (1808-1892). Había recorrido gran parte del mundo y no quería perderse la experiencia de esta guerra que tanto tenía que ver con su país y, como lo comprobará a poco de pisar puerto, tanto más tenía que ver con su lengua y su cultura. Una reseña bibliográfica del Comercio del Plata, en octubre del 1845, daba cuenta del reconocimiento a su obra o, por lo menos, de la existencia de una pieza bibliográfica en Montevideo. Eso explica la facilidad con que este escritor, insomne andariego y traductor de E.T.A. Hoffman, entró en contacto con lo mejor de la inteligentsia de la ciudad, seguramente ávida por conocerlo, y a la que en su narración autorreferente presentó con admiración. Si se exceptúan algunas exageraciones y varios retaceos a los sitiadores, Marmier realizó uno de los pocos diagnósticos que conocemos sobre los impresos, su circulación, los posibles públicos y hasta el destino de sus mediadores en el Río de la Plata:

[...] la publicación de un manuscrito está subordinada a circunstancias que pondrían miedo al más intrépido editor

5 El 12 de febrero del 46 aparece otro aviso que complementa este: "AVISO. Una señora francesa que llega ahora de Europa, desea hallar una casa de familia, que tenga niños, para encargarse de su educación y enseñarles la lengua francesa; para lo que se ofrece á habitar en la misma casa. Ocúrrase á la calle del 25 de mayo $N^{o} 178$, peluquería de Julio" ( $\mathrm{N}^{\mathrm{0}}$ 110: 4, col. 3). De paso, podemos averiguar en el mismo periódico que en la "peluquería de Julio" se vendían guantes de cabretillo "para hombres, y señoras [...] y guantes de colores sumamente baratos". 
Rocca, P. La guerra de los textos, los textos en la guerra parisiense. En primer lugar, el círculo de lectores se halla reducido casi por entero a las murallas de Montevideo. [...] Queda, es verdad, a los escritores de Montevideo, cierta cantidad de lectores seguros en Chile, Perú y en otros estados de América del Sur. ¡Pero el pobre libro se ve obligado a hacer un viaje muy largo para alcanzarlos!... Debe atravesar en contrabando las provincias argentinas, o doblar por el Cabo de Hornos y necesita varios meses para llegar al otro lado de la cordillera. [...] En segundo lugar, a medida que la ciudad se ha empobrecido por la duración del sitio, parte de los obreros impresores la han abandonado para buscarse trabajo más lucrativo. [...] Además, por influencia del bloqueo, las imprentas han carecido varias veces de elementos primordiales, de tipos nuevos para sus cajas, y del papel necesario.

-He visto que ha aumentado el tamaño de su diario -le dije un día al fundador de una publicación-; sin duda aumenta el número de los lectores.

-iAy, no! -me respondió- se ha agotado el papel de los primeros números y no hemos podido encontrar otro de iguales dimensiones (MARMIER, 1967, 108-109).

Puede que esa fuera la situación en 1850. Sin embargo, ese fue uno de los años de mayor actividad editorial en Montevideo, tal vez como consecuencia de la maduración interna de tendencias estéticas y discursivas; a pesar de que durante todo el año faltó todo tipo de recursos y se vivía con el concreto riesgo de que la ciudad se precipitara en manos del enemigo. El movimiento comercial en 1845-46 aporta resultados mucho mejores que los declarados por Marmier. El acucioso registro del Comercio del Plata deja claro que se importaba casi todo lo que consumía en Montevideo en el rubro que fuere, y entre esos productos el papel, la tinta y los libros llegaban en proporciones respetables, quizá capaces de cubrir las demandas para la escritura de los individuos, para los impresos usuales (periódicos, hojas, algunos pocos libros), para la venta de libros y, también, para la ejecución del canto acompañado por la guitarra evidentemente cada vez más difundida entre los sectores populares. Considérense algunos datos: el 3 de octubre de 1845 se da a conocer la llegada reciente de 2 cajones de papel de carta, 4 de imprenta, 24 de papel común y 217 balas de estraza. No figura el ingreso de libros u otros impresos, y no porque el detalle no sea preciso, ya que aparecen, por ejemplo, galletitas y distintos tipos de vino. El 7 de octubre se informa que una barca española transportó hasta Montevideo " 3 cajones de libros [...] De tránsito para los puertos del Pacífico: 5 cajas libros”. Comparativamente el número no es menor. En el extracto informativo sobre los artículos importados en setiembre del 45 que han ingresado por el Puerto aparecen 12 cajones de 
Rocca, P. La guerra de los textos, los textos en la guerra papel de imprenta, 108 balas de papel blanco y 124 de estraza más 11 cajones de tinta venida de "Norte-América". A fines del mes siguiente llegó más tinta en una barca francesa procedente de Burdeos, como se informa el 24 de octubre: dos cajones, y junto a ella un cajón con libros. El 4 de noviembre se anuncia que un bergantín que había zarpado de Bremen trajo, entre otras mercancías, un cajón con libros. Y en el resumen de lo que ingresó por el puerto en octubre, difundido en el $\mathrm{N}^{\mathrm{o}} 52$ del $1^{\mathrm{o}}$ de diciembre se encuentran: "Cuerdas de guitarra, 3 cajones. Guitarras, 8. Libros impresos, 11 cajones [...]. Papel blanco común, 1.942 balas, 14 cajas y 2 baúles. Tinta de escribir, 1 cajón frascos” (pág. 3, col. 1). Por tan detallado escrutinio se puede saber que de Brasil sólo viene papel de estraza, de Génova un cajón de libros impresos y de Norteamérica un cajón de "libros en blanco". A fin de año ( $\mathrm{N}^{\mathrm{o}} 75,30$ de diciembre), otro balance indica que han entrado 2 cajones de cuerdas de guitarra, 23 cajones de libros impresos (de Francia llegan 5) y 433 balas de papel blanco común. Por último, el 7 de febrero ( $\left.\mathrm{N}^{\mathrm{o}} 106\right)$ el movimiento no ha mermado en intensidad en los rubros que nos interesan: 1 cajón de cuerdas de guitarra, 1 cajón con guitarras, 20 cajones y 2 baúles con libros, de papel blanco llegan " 23 fardos, 90 balas, 200 resmas, 2 cajones” y 1 barril de tinta. De España proceden 2 baúles y 16 cajones de libros, de Francia, 3 cajones.

Aun si este flujo hubiera descendido cuatro años después a los niveles críticos que comenta Marmier, que el "principal diario de Montevideo" no tenga "más de cuatrocientos abonados" representa un guarismo muy alto. Se trata de casi un cinco por ciento de la población total de la ciudad sitiada. Puede conjeturarse que los lectores competentes en lengua española apenas rozaban en ese espacio, en cálculos muy optimistas, entre diez y once mil, por lo que el porcentaje anterior aumenta sólo tomando en cuenta una publicación, y eso por más que sea la más leída.

Los libros franceses conseguían llegar a Montevideo. Un factor de enorme peso debió haber tenido la numerosa colonia francesa, más de un tercio de la población de la ciudad en 1845 según los cálculos más aceptados (Arredondo, 1928). Su presencia -así como la de la creciente colonia italiana- debió ayudar mucho a los prestigios de un idioma que pronto dejó de sonar extraño para oídos educados en castellano. Para obtener impresos franceses eran insuficientes los buenos oficios de un solo librero. En el comentado catálogo de 1837 el librero Hernández consigna una sección especial para libros en esa lengua, la mayor parte de los cuales son de literatura y filosofía: obras varias de Chateaubriand, que no especifica (y que previsiblemente duplica la mencionada Atala), otras de Moliére, de Rousseau, etc. Son apenas quince títulos, presentados con la imperfección habitual de esa lista, pero son los únicos en otra lengua que no sea la española, y con el agregado de que muchos otros aparecen en otras líneas del folleto en traducción, desde piezas de Voltaire hasta, por ejemplo, la Historia de la revolución francesa de Thiers ilustrada con "cien láminas". La colectividad 
Rocca, P. La guerra de los textos, los textos en la guerra francesa podía conseguir libros con sus parientes de ultramar, tal vez, con mayor facilidad y hacerlos circular y hasta venderlos, como lo hizo en su "institution" el Abbate Paul, según se lo difundió durante casi tres meses en Le Patriote Français, uno de los periódicos de la colectividad en Montevideo:

Livres à vendre récemment reçues de Paris et que se trouvent de resto dans l' institution de l'Abbate Paul, rue du 25 de maie 342 : Almanaque Français- espagnol et espagnol-français, reliure très riches; id. tout en français; Dictionnaire français-espagnol et espagnol-français pour Taboada. Histoire de Napoleon avec portraite, plains de bataille, etc. par Norvine. Physique avec planches par Biot. Geudeisie ou Traite de la figure de la terre, comprenant la topographie, l' Arpentage, le nivellement, la Geomorphie terrestre et astronomique, la construction de cartes, etc. par Francoeur, professeur de la faculté de sciences de Paris. Euvres complètes de Mirabeu; Histoire de la révolution française par Thiers; Cartes géographiques séparées. Matemáticas. Gramática de Chantreau. (“Avis important”, No 184,16/ IX/1843, 4, cols. 2-3).

Los representantes de países extranjeros que gozaban de mayores prerrogativas y de una renta que les permitía sortear las penurias generales podían pedir los libros a sus lugares de origen. Es el caso del quisquilloso e inteligente Rodrigo de Sousa da Silva Pontes. Para nuestra fortuna este diplomático brasileño detalló en su diario varias de las remesas de libros que consiguió de Rio de Janeiro por intermedio del cónsul de su país en Montevideo o de otros funcionarios. Desde marzo de 1846 hasta noviembre de 1848 figuran siete encomiendas de un promedio de diez volúmenes cada una. En sus pedidos comparecen diccionarios, almanaques (el Gotha para cada uno de esos años; el de Rio de Janeiro), títulos de historia política y militar europeas y americanas, algún texto científico, las obras de Villemain, pero ni una sola novela (Souza da Silva, 1983, 277, 292-93, 295, 304, 311 y 329). Alguna de estas piezas con un poco de paciencia pudo haberlas comprado en Montevideo, pero tal vez el funcionario brasileño prefirió el canal diplomático porque era más económico o más cómodo y, además, porque en sus remesas podía incluir libros de su país que se le facilitaban por ser miembro del Instituto Histórico e Geográfico do Brasil. En sus lecturas, Sousa privilegiaba la historia y la ciencia y descartaba la ficción, pero asumía el mundo del espectáculo en cuanto entretenimiento. Concurría asiduamente al teatro (tres veces, por ejemplo, lo hace entre el $1^{\circ}$ y el 14 de enero de 1851), aun sobreponiéndose a las capacidades interpretativas de los actores, que deplora. Nunca menciona siquiera una solitaria visita a cualquier librería o local semejante en Montevideo. 
Rocca, P. La guerra de los textos, los textos en la guerra
En el campo sitiador los libros circulaban con mayor dificultad porque la organización de la Villa Restauración se fue estructurando lentamente alcanzando, sólo hacia 1849, cierto perfil urbano capaz de superar la condición de un tumultuoso campamento y luego de un precario caserío, surcado de caminos y calles de tierra recién abiertos, donde vivían civiles, muchos de los soldados con sus familias que llegaban de remotos lugares a medida que se demoraba el asalto final. A partir del examen del periódico El Defensor de la Independencia Americana el principal cronista del gobierno del Cerrito registró dos librerías: la de Perdomo, instalada en mayo del 49, y la del Sr. Larravide, provista de "un surtido general de los mejores autores de Derecho, Historia, Instrucción, Poesías y Novelas", en los dos casos junto a la venta de otras mercancías (Magariños de Mello, 1954, 103-104). Los libros y periódicos cuyos extractos se utilizan para armar El Defensor de la Independencia Americana y que, muy ocasionalmente, son mencionados en sus modestos avisos debían llegar a través del puerto sitiado en el Buceo, cuyo movimiento era intenso y estaba garantizado por una gran fuerza militar. A pesar de estas garantías la bibliografía más moderna circulaba en cuentagotas. Prueba de ello es que hacia el final de la guerra el acaudalado Antonio Rius pedía a Rio de Janeiro libros franceses y, clandestinamente, los solicitaba también a un señor de esta nacionalidad residente en Montevideo, quien le informó que sus diligencias para conseguir la obra de Thiers habían sido infructuosas. Por la misma época, el rudo coronel Ignacio Oribe, hermano del jefe supremo del sitio, le encomendó al coronel Lasala buscar un ejemplar de "la Nueba (sic) Troya pues tiene mil deseos de leerla" (Magariños de Mello, 1954: 105-106). En ese cruce último los textos y la guerra, el presente y el mito pisaban un extraño límite, que continúa desafiando las formas y su historia. 
Rocca, P. La guerra de los textos, los textos en la guerra
Referências

ANÓNIMO (1990). "La caja de costura (Cuadro de Leo Lespés, contorneado por una señorita)", en Narraciones breves uruguayas, Leonardo Rossiello (antología y prólogo). Montevideo: TAE, p. 211-215. [Originalmente en La Semana, Montevideo, 20/XII/1857].

ARREDONDO, Horacio (1928). "Los «Apuntes estadísticos» del Dr. Andrés Lamas". Montevideo, Imprenta de El Siglo Ilustrado. (Apartado de la Revista del Instituto Histórico y Geográfico del Uruguay, Montevideo, Tomo VI, N ${ }^{\mathrm{o}}$ 1, p. 25-195). [1842].

BRACONNAY, Claudio María (1943). La Legión francesa en la Defensa de Montevideo. Montevideo, Claudio García. (Prólogo de Raúl Montero Bustamante).

CÂMARA CASCUDO, Luís (1953). Cinco livros do povo. Rio de Janeiro, José Olympio.

Catálogo de los libros ecsistentes en la librería de Jaime hernandez, Diciembre 4 De 1837 , CAlle de s. Pedro Junto a la sala de Comercio, $\mathrm{N}^{\circ} 1$ (1838). Montevideo, Imprenta de la Caridad.

GREENE ARNOLD, Samuel (1951). Viaje por América del Sur (1847-1848). Buenos Aires, Emecé. (Prólogo de David James. Traducción de Clara de la Rosa).

GRÜNWALDT RAMASSO, Jorge (1970). Vida, industria $y$ comercio en el antiguo Montevideo (1830-1852). Montevideo, Barreiro y Ramos.

LEFRÊRE, Jean-Jacques (1998). Isidore Ducasse. Auteur des Chants de Maldoror, para le comte de Lautréamont. Poitiers, Librairie Arthème Fayard.

MAGARIÑOS DE MELLO, Mateo J. (compilación, estudio preliminar y notas) (1954). El gobierno del Cerrito. Colección de documentos oficiales emanados de los poderes del gobierno presidido por el Brigadier General D. Manuel Oribe 1843-1851. Montevideo, Imprenta El Siglo Ilustrado, tomo II.

MASCARÓ Y SOSA, Pedro (1882). "Apuntes para una historia de la Biblioteca Nacional", en Anales del Ateneo del Uruguay, Montevideo, Año I, Tomo II, N 9.

MEYER, Marlyse (2005). Folhetim. Uma história. São Paulo, Companhia das Letras. (Prólogo de Antonio Candido). [1996].

POUCEL, Benjamín (2001). Los rehenes de Durazno. Observaciones, estudios y episodios históricos relevados en treinta años de residencia en el Río de la Plata. Montevideo, El Galeón/El Calafate. (Traducción de Alicia Mercedes Chiesa). [1864]

PRADERIO, Antonio (1962). Índice Cronológico de la Prensa Periódica del Uruguay, 1807-1852, Antonio Praderio. Universidad de la República/Facultad de Humanidades y Ciencias. (Advertencia de Eugenio Petit Muñoz). 
Rocca, P. La guerra de los textos, los textos en la guerra
PRIETO, Adolfo (1996). Los viajeros ingleses y la emergencia de la literatura argentina, 1820-1850. Buenos Aires, Sudamericana.

ROCCA, Pablo (2012). "Machado de Assis, escritor del Río de la Plata”, en Un experimento llamado Brasil y otros estudios, Pablo Rocca. Ediciones de la Banda Oriental/ Embaixada do Brasil em Montevidéu.

ROCCA, Pablo (2015). "Libros, esclavos y otras mercancías (Jaime Hernández y la trama cultural de la República entre 1834 y 1844), en Theomai, Universidad de Quilmes, $\mathrm{N}^{\circ} 31$, primer semestre. (Número coordinado por Alcides Beretta Curi), p. 146-162. http://revista-theomai.unq.edu.ar/NUMERO 31/Index.htm

SCARONE, Arturo (1916). La Biblioteca Nacional de Montevideo. Montevideo, Talleres Gráficos del Estado.

SOUSA DA SILVA PONTES, Rodrigo (1983). Diario[s] particulares, 1843 a 1849 e 1851, en Revista do Instituto Histórico e Geográfico Brasileiro. Anais do Congresso de História do Segundo Reinado, Rio de Janeiro, p. 229-434. (Presentación y notas de José Antônio Soares de Souza).

THÉRENTY, Marie-Eve (2013). "El folletín en los periódicos del siglo XIX: ¿hecho literario o fenómeno social?”. La invención de la cultura mediática. Prensa, literatura y sociedad en Francia en el siglo XIX. México, Instituto Mora. (Edición y presentación: Laura Suárez de la Torre. Traducción: Ana García Bergua), p. $11-29$.

WEINHARDT, Marilene (2000). Mesmos crimes, outros discursos? Algumas narrativas sobre o Contestado. Curitiba, Editora da UFPR.

Submetido em 16/9/2016

Aceito em 24/9/2016 